\title{
Impact of Dietary Counseling on the Anthropometric Indices, Biochemical Profile, and Sports Performance of Adolescent Badminton Players
}

\section{Arpana Indoria ${ }^{1 *}$ and Nimali Singh ${ }^{2}$}

${ }^{1}$ Research Scholar and Department of Home Science, University of Rajasthan, Jaipur, India

${ }^{2}$ Associate Professor and Department of Home Science, University of Rajasthan, Jaipur, India

*Corresponding Author: Arpana Indoria, Research Scholar and Department of Home Science, University of Rajasthan, Jaipur, India.
Received: July 03, 2021

Published: August 06, 2021

(C) All rights are reserved by Arpana Indoria and Nimali Singh.

\begin{abstract}
Introduction: Athlete and their coaches should pay specific attention to nutrition because diet is an imperative part of sports performance. Adequate nutrition provides the body compensation for improved energy loss and dietary needs and supports supreme adaptation to physical load. Sports performance and exhaustion acquired by adolescent athletes during aerobic training that reliant on carbohydrate stores in the body and carbohydrate needs during the physical session.

Aim: To study the impact of dietary counseling on anthropometric indices, biochemical profile, and sports performance of adolescent badminton players in the age group 10 - 12 years.

Methodology: The present study was conducted at a Badminton Academy. Sixty adolescent athletes participated in 12-week intervention program. Students were purposively selected in to control group $(n=60)$ and Badminton group $(n=60)$. Anthropometry measurements were recorded, and biochemical estimations were carried out. Intervention was carried out through counseling, using IEC material, discussions and sharing of healthy recipes. The children were also given one to one counseling on importance of nutrition, hydration, and impact of meals prior to an event, during event and post event and its role in sport performance. Physical fitness test consisting of endurance, flexibility, shuttle run test, agility, leg rising, crunches, zig-zag run and speed were assessed at pre and post intervention.

Results: The results indicate that there was a significant improvement in weight, height, and waist to hip ratio of badminton players. There was also a significant improvement in the biochemical parameters such as hemoglobin and serum calcium, the vitamin D status also improved but the change was found to be statistically non-significant. Physical fitness parameters were also improved including flexibility, speed and 50-yard desk among adolescent.

Conclusion: The study indicates that intervention through nutrition counseling positively improved anthropometric indices and biochemical profile and physical fitness score of children. These finding suggest that fitness program with sports performance test would be more effective and encourage physical fitness among adolescents.
\end{abstract}

Keywords: Physical Activity; Flexibility; Speed; Nutrition; Hemoglobin

Citation: Arpana Indoria and Nimali Singh. "Impact of Dietary Counseling on the Anthropometric Indices, Biochemical Profile, and Sports Performance of Adolescent Badminton Players". Acta Scientific Nutritional Health 5.9 (2021): 30-39. 


\section{Introduction}

Badminton is considered with work of short, medium, and high intensity paired with altering the temporal structure. Core muscle comprises transverse abdominal muscle, stomach internal, and external oblique muscle. Core muscle delivers internal pressure to expel elements and assist in the stabilization of the pelvis and thorax in dynamic movements. The core exercise of muscles reduces the risk of a knee injury. The crucial component of core stability is strength, endurance, power, and coordination with muscle, hip, and abdominal muscle [1].

The speedy movement of the whole body with alteration in the stimulus like when a badminton player hit the shuttlecock is termed agility [2]. A study by Young, Dawson, and Henry, 2013 [3] stated that agility depends on various factors such as leg muscle strength, straight sprint, and running practice indicating that agility needs muscle power for quick movements. Similarly, another study by Okada, Huxel, and Nesser, (2011) [4] described that an athlete should involve in a training exercise that is like the body movement of sports-related motion and movement during competition. Reach your peak sports performance involves muscle power, muscle strength, and stability and that core stability is more significant for badminton players. The core muscle includes muscle stretching that increases muscle coordination amid lower and upper extremities and cuts down injury risk and enhances sports performance. So, in the end, core strength and agility must need for badminton players [5].

Nutrition intervention research program for badminton player's target in improving dietary knowledge and help in positive dietary modifications to increase sports performance, wellbeing, and better health [6].

Young athletes developed from childhood through adolescence and reached fully into adulthood stage and this stage is called reproductive phase. Adolescent experience various changes like physiological, anatomical, and metabolic and in the end maturation and biological growth. It is a complex stage that is impacted by hormones, nutrients, genes, and environment [7].

The primary aim of an athlete should be ensuring that they meet nutritional requirement for maturation and growth. There are several factors that affect an athlete nutritional needs and those are growth rate, anthropometric indices, maturity timing, their recent metabolic and physiological abilities, exercise, and sport demand [8].

\section{Nutrient requirements for sport performance}

An athlete's energy requirement is delivered through the intake of carbohydrates, protein, and fat. The energy intake of an individual should be calculated based on total energy expenditure. The total energy requirement is made of three factors consisting of basal metabolic rate, thermoneutral stage, and the amount of energy needed to keep normal homeostatic levels. Diet-induced thermogenesis is also known as the thermic effect of food, the energy cost of digestion, absorption, and transportation, storage of drink and food [9]. However, resting metabolic rate is the largest element of energy expenditure. Young adolescent athletes have a high training load and high total energy expenditure. Energy availability is defined as the growth and energy left for homeostatic physiological function. Active energy expenditure is a constituent of total energy expenditure and it is affected by body size and motion. The type of game, their duration, intensity all impacted by active energy expenditure:

(Energy availability = Energy intake- active energy expenditure).

Low levels of energy availability ( $<30 \mathrm{kcal} / \mathrm{kg}$ FFM d) may harm maturation of tissues, impaired growth, decreased skeletal bone mineral density, risk of a stress fracture, osteoporosis, and late sexual maturation, repress immune system and affect their sports performance, long term psychological and physical health. So, the recommended energy availability is $45 \mathrm{kcal} / \mathrm{kg}$ FFM. day to sustain normal body physiological function [10].

The intake and quantity of macronutrients (carbohydrates, protein, and fat) requirement depends upon how nutrient-training interactions affect energy system, availability of substrate and training modifications. Physical activity is fueled by combined series of energy system that involves aerobic pathway (carbohydrate and fat oxidation) and non-oxidative pathway (Phosphagen and glycolytic). ATP (Adenosine triphosphate) and phosphocreatine supply rapidly available energy sources for muscle contraction [7].

The anaerobic glycolytic pathway breaks down muscle glycogen and glucose through the glycolytic cascade and it is the chief

Citation: Arpana Indoria and Nimali Singh. "Impact of Dietary Counseling on the Anthropometric Indices, Biochemical Profile, and Sports Performance of Adolescent Badminton Players". Acta Scientific Nutritional Health 5.9 (2021): 30-39. 
pathway maintaining high intensity exercise for 10-180 seconds. Oxidative pathway supports the primary fuel for exercise lasting more than two minutes. The main substrate consists of liver and muscle glycogen, intramuscular lipids, amino acid for liver, muscle, gut, and blood. Oxygen is required for working muscles and the body uses aerobic pathway to a greater extent and less of anaerobic pathway. The frequency, duration, intensity, type of training, sex, pre nutrient intake and substrate availability decides the use of pathways [7].

An appropriate diet help in an athlete optimal body function, regulate the role of macronutrient and micronutrient intake and supports in operating body functions. An athlete energy needs rest on period of training and cycle of competition, and it will differ from day to day and slight changes in the intensity and volume. There are some elements that affect athlete energy needs such as contact with heat or cold, anxiety, fear, mental stress, injury and some drugs like nicotine and caffeine.

Carbohydrate has an important role in sports performance. Firstly, the body carbohydrates stores are limited, and it can be manipulated by dietary intake on the daily basis or a single session of exercise. Secondly, carbohydrate is vital fuel for central nervous system and brain and act as a substrate for muscular work that maintain muscles for exercise intensity in the aerobic pathway and oxidative pathways. Carbohydrates provides benefits over fat as a substrate because it helps in greater production of ATP/volume of $\mathrm{O}_{2}$ and it can be directly delivering to the mitochondria and improves exercise efficiency. The amount of glycogen and its locality within the muscle cell modifies metabolic, physical, and hormonal environment that sign response to exercise applied [10].

Glycogen reduction in the body is a major cause of exhaustion in both high intensity and endurance exercise, it is important that adolescent athletes eat enough amount of carbohydrates in their daily diet for sports performance and recovery from injury after competition and training. Adolescent athletes do not have the same capacity to store glycogen as adult athletes have. Once exogenous carbohydrate is eaten during physical activity, the oxidation rate of carbohydrates in relation to body mass index is higher among adolescents than in adults. As a result, the relative impact of exogenous carbohydrates on total energy expenditure is higher in young athletes than adolescents [11].
During exercise carbohydrate intake for an adolescent are like adult athletes and in moderate to high-intensity exercise lasting longer than sixty minutes, an athlete should include 30 - 60 g/ hour and they should not include more than one gram per minute of carbohydrates. It is recommended to drink liquid form of high glycemic index carbohydrates because it provides other benefits on liquid intake. It should be given to athletes in a form of six percent carbohydrate drink, if carbohydrate consumption is more than $6 \%$ it may cause gastric discomfort among adolescents [11].

Phillip., et al. 2010 [12] described that intake of $500 \mathrm{ml}$ six percent carbohydrates solution during high-intensity exercise increases physical ability among twelve- to fourteen-year-old boys and it should be a mixture of six percent glucose and fructose solution for adolescents. In the end, it improves $40 \%$ in a time to exhaustion to test. An adolescent athlete should include $1.2 \mathrm{~g} / \mathrm{kg}$ body weight per hour of high glycemic index carbohydrates instantly post exercise because it improves blood glucose levels and help in glycogen resynthesis [13].

The amount of carbohydrates depends upon recovery time, intensity, and duration of training exercise. Fruit juices and dairy products are more beneficial in boosting liver glycogen storage immediately after exercise. A milk-based smoothie like milk with banana and addition of dry fruits in it is a good choice, a bowl of cereals and flavored milk or chocolate milk because it consists of all nutrients. Therefore, an athlete should include $6-10 \mathrm{~g} / \mathrm{kg}$ of body weight daily carbohydrate intake [12].

Protein is a crucial macronutrient for tissue growth among adolescents. It delivers amino acid to synthesis of thousand of enzymes that is essential for providing energy from the break down of fat and carbohydrates. Leucine, isoleucine, and valine are important amino acids (branched chain amino acid) and help in the synthesis of protein especially leucine [13]. An athlete is recommended to consume protein (1.4 - $2 \mathrm{~g} / \mathrm{kg}$ of body weight) and they should maintain positive nitrogen balance. An example $50 \mathrm{~kg}$ adolescent athlete requires 70 - $100 \mathrm{~g}$ of protein per day and protein should be distributed in the breakfast so the whole body can balance positive energy balance [14].

Protein consumption is important chiefly before and after exercise and intake of only five-gram protein after exercise improve amino acid availability and maintain positive nitrogen balance, in-

Citation: Arpana Indoria and Nimali Singh. "Impact of Dietary Counseling on the Anthropometric Indices, Biochemical Profile, and Sports Performance of Adolescent Badminton Players". Acta Scientific Nutritional Health 5.9 (2021): 30-39. 
take of 10 - 15g protein within six hours of post exercise sustains positive protein nitrogen balance [10].

An adolescent athlete should consume protein rich drink before going to bed. It is also suggested that leucine rich foods including dairy products like cheese, milk and yogurts, fish, egg, poultry, and meat helps in muscle protein synthesis. They must consume pulses, beans, nuts, oilseeds etc. (But these food sources are deficient in essential amino acids). Soyabean is the only plant-based protein that contains all essential amino acids [14].

Dietary fat has significant role in the absorption of fat-soluble vitamins, and it delivers omega - 3 and omega- 6 fatty acids that cannot be formed in the body and hence must be consumed through the diet [15]. During 60 - 90 minutes of exercise, it generates energy from fat. Young adolescent athletes must consume natural sources of fat especially high in omega-3 fatty acids consisting of dry fruits, nuts, and seeds [16].

During exercise fat and carbohydrates are the main base of ATP production, because fat provides energy during moderate to low exercise [17]. Overuse of fats in daily diet leads to oxidative stress that affects metabolic functioning (Fisher-Wellman and Bloomer, 2010). Fish oil comprises 2 essential fatty acids including EPA (eicosapentaenoic acid) and DHA (docosahexaenoic acid). Consumption of fish oil improve cardiovascular health and reduce inflammation that decreases recovery time between exercise [15].

The ACSM guidelines recommend athletes to drink 5 - $7 \mathrm{ml}$ per $\mathrm{kg}$ of body weight four hours before exercise. Hydration is more important for best sports performance. Proper hydration helps in the thermoregulation and cooling the body. Fluid is imperative for optimal sports performance of badminton adolescent athletes. Sweat and respiratory fluid losses are high in badminton as courts are often very hot and crowded. Air-conditioning may not be in use. Water transport nutrients and oxygen to brain and muscle and maintains normal blood pressure. The main role of water is absorption and digestion of nutrients. It acts as a cushion to the brain and lubricate the joints [18].

One percent fluid loss is linked with falling off sports performance whereas two percent water loss is relating to ten percent loss of $\mathrm{VO}_{2}$, weakened immune system, poor coordination, increased chances of injury, decreased $\mathrm{O}_{2}$ delivery to muscles and an athlete get exhausted [19].
Iron and calcium deficiency are more common among adolescents. Specifically, iron and calcium are frequently noted as common nutritional concerns among children and adolescents. Requirement of iron are greater among girls than boys because of menses. Anemia affects their sport performance. Adolescent should consume more iron rich foods like ground nut, dry fruits, fortified cereals, green leafy vegetables and red meat and foods rich in ascorbic acid such as lemon, malta, orange, amla etc. [20].

Calcium demands are highest during adolescence $1300 \mathrm{mg} /$ day for both girls and boys because it helps in the gaining of bone mass that reach over the pubertal ages. Calcium food sources are milk and milk products, almonds, broccoli, fortified juice etc. Beside this calcium absorption depends upon vitamin D [20].

Physical activity is an element that is related to the ability to perform the regular task without fatigue. It is an important health sign because it shows a positive fitness score and positive effect on the physical and mental health of adolescents and reduces various health problems [20].

Physical fitness items included flexibility, agility, shuttle run test, crunches, 50-yard desk, speed. The flexibility test is reaching ahead as far as possible from a seated position, to measure the shoulder and wrist flexibility of the experimental group; both hands were positioned on top of each other in the facedown position. On the mechanism placed opposite the athlete, student was asked to raise her/his arms without elevating his body from the ground. it was measured in centimeters and two attempts have observed the physical score [21].

Agility is running between two lines 10 meter apart to pick up small blocks. The student is stand with toes just behind the starting line and Run across to pick up one block and return to place it behind the starting line. Student need not to place the second block behind the starting line, just run through the finishing line [22].

Shuttle run test assesses cardio-respiratory fitness of the students and it is more common physical test of aerobic fitness. A shuttle run test is running and touching shuttle and then turning to a start point at higher speed (two parallel lines are pulled on the floor with white chalk five meters apart and time has recorded completion of five cycles [21].

Citation: Arpana Indoria and Nimali Singh. "Impact of Dietary Counseling on the Anthropometric Indices, Biochemical Profile, and Sports Performance of Adolescent Badminton Players". Acta Scientific Nutritional Health 5.9 (2021): 30-39. 
Speed is a running a single maximum sprint over 50 meters with the time recorded start from a stationary standing position with one-foot front of the other. The front foot must be behind the starting line. Once the student is ready, the coach gives the instruction "Set" then "Go" and student should be encouraged to not slow down before crossing finish line [21].

Sits-ups is for testing endurance and strength, a maximum number of sits up to have observed in thirty seconds [21].

\section{Methodology}

Children playing badminton in the age group of $10-12$ years were recruited for the study using purposive random sampling method. The children were selected based on their willingness to participate in the intervention study. Interview schedule was designed to elicit information and measurements for anthropometry, biochemical parameters and sport performance test were carried out. Sports performance test were conducted including flexibility test, shuttle run test, speed, 50-yard desk, crunches.

\section{Nutrition education}

Nutrition education intervention program was planned for sports athletes consisting of dietary counseling along with parents, suggestion of recipes, dietary practice, and importance of meal during pre, post and during training etc. The sports adolescent athletes were assessed prior to and post the nutrition intervention program.

The data was collected, tabulated, and statically analyzed using mean value, frequency, percentage standard deviation, and mean value.

\section{Results and Discussion}

The level of nutritional knowledge for young athletes impacts his/her food choices and behaviors. Poor knowledge regarding correct eating behavior may lead to an increase in unhealthy dietary habits and bad eating behavior. The mean value of the weight, height, BMI, waist to hip ratio, mid arm muscle circumference, mid upper arm circumference, waist, and hip circumference, skinfold thickness at post intervention was compared with values at pre intervention in adolescent badminton male and female athletes. It was found that there was an increase in mean weight and height in both the male and female experimental group and the difference was found in weight category statically significant $(\mathrm{P}<0.02)$ and highly significant in height $(\mathrm{P}<0.000)$ category (Table 1$)$.

\begin{tabular}{|c|c|c|c|c|c|c|}
\hline \multirow{2}{*}{ Variable } & \multicolumn{3}{|c|}{ Control } & \multicolumn{3}{|c|}{ Experimental } \\
\hline & Pre & Post & t value & Pre & Post & t value \\
\hline Weight (kg) & $\begin{array}{c}41.7 \pm \\
13.8\end{array}$ & $\begin{array}{c}41.9 \pm \\
13.7\end{array}$ & $3^{*}$ & $\begin{array}{c}43.83 \pm \\
9.06\end{array}$ & $\begin{array}{c}44.27 \pm \\
9.08\end{array}$ & $2.39 *$ \\
\hline Height $(\mathrm{cm})$ & $\begin{array}{c}149 \pm \\
8.4\end{array}$ & $149 \pm 8.4$ & $2.5 \mathrm{NS}$ & $\begin{array}{c}148.65 \pm \\
8.22\end{array}$ & $\begin{array}{c}149.78 \\
\pm 8.42\end{array}$ & $4.1^{* *}$ \\
\hline BMI $\left(\mathrm{kg} / \mathrm{m}^{2}\right)$ & $\begin{array}{c}18.20 \pm \\
4.2\end{array}$ & $\begin{array}{c}18.29 \pm \\
4.2\end{array}$ & $2.34 \mathrm{NS}$ & $\begin{array}{c}19.78 \pm \\
3.50\end{array}$ & $\begin{array}{c}19.65 \pm \\
3.26\end{array}$ & $0.94 \mathrm{NS}$ \\
\hline WHR (cm) & $\begin{array}{c}0.90 \pm \\
0.85\end{array}$ & $\begin{array}{c}0.91 \pm \\
0.78\end{array}$ & $1.93 \mathrm{NS}$ & $\begin{array}{c}0.81 \pm \\
0.67\end{array}$ & $\begin{array}{c}0.85 \pm \\
0.71\end{array}$ & $3.1 \mathrm{NS}$ \\
\hline MUAC (cm) & $\begin{array}{c}13.5 \pm \\
1.2\end{array}$ & $\begin{array}{c}13.4 \pm \\
1.18\end{array}$ & $1.51 \mathrm{NS}$ & $\begin{array}{c}13.5 \pm \\
1.06\end{array}$ & $\begin{array}{c}13.4 \pm \\
0.7\end{array}$ & $0.12 \mathrm{NS}$ \\
\hline MAMC $(\mathrm{cm})$ & $\begin{array}{c}6.71 \pm \\
0.59\end{array}$ & $\begin{array}{c}6.73 \pm \\
0.59\end{array}$ & $0.707 \mathrm{NS}$ & $\begin{array}{c}7.33 \pm \\
1.93\end{array}$ & $\begin{array}{c}6.74 \pm \\
0.36\end{array}$ & $0.17 \mathrm{NS}$ \\
\hline WC $(\mathrm{cm})$ & $\begin{array}{c}27.99 \pm \\
4.11\end{array}$ & $\begin{array}{c}28.23 \pm \\
4.05\end{array}$ & $1.3 \mathrm{NS}$ & $\begin{array}{c}26.83 \pm \\
2.95\end{array}$ & $\begin{array}{c}27.52 \pm \\
3.38\end{array}$ & $1.8 \mathrm{NS}$ \\
\hline $\mathrm{HC}(\mathrm{cm})$ & $\begin{array}{c}32.75 \pm \\
4.34\end{array}$ & $\begin{array}{c}32.57 \pm \\
4.45\end{array}$ & $1.9 \mathrm{NS}$ & $\begin{array}{c}31.93 \pm \\
3.28\end{array}$ & $\begin{array}{c}32.18 \pm \\
3.76\end{array}$ & $0.8 \mathrm{NS}$ \\
\hline SFT $(\mathrm{cm})$ & $\begin{array}{c}14.76 \pm \\
2.79\end{array}$ & $\begin{array}{c}13.45 \pm \\
1.7\end{array}$ & $1.9 \mathrm{NS}$ & $\begin{array}{c}13.42 \pm \\
3.64\end{array}$ & $\begin{array}{c}13.3 \pm \\
2.82\end{array}$ & $0.16 \mathrm{NS}$ \\
\hline
\end{tabular}

Table 1: Mean anthropometric measurements of female badminton players.

NS- non-significant, *Significant, ${ }^{* *}$ Highly Significant.

In the control group, the mean weight was also increased (41.7 \pm 13.8 to $41.9 \pm 13.7 \mathrm{~kg} / \mathrm{m} 2$ ) in both the groups and found statically significant $(\mathrm{P}<0.02)$. The mean body mass index was reduced in female athletes $\left(19.78 \pm 3.50\right.$ to $\left.19.65 \pm 3.26 \mathrm{~kg} / \mathrm{m}^{2}\right)$ and male athletes $\left(19.78 \pm 3.50\right.$ to $\left.19.65 \pm 3.26 \mathrm{~kg} / \mathrm{m}^{2}\right)$ in the experimental group while in the control group it has increased in both male and female category.

There was a significant improvement in the waist to hip ratio in both male and female experimental groups at pre to post-intervention. The mean waist to hip ratio of female athletes was $(0.81$ $\pm 0.67 \mathrm{~cm}$ to $0.85 \pm 0.71 \mathrm{~cm})$ and male $(0.88 \pm 0.08 \mathrm{~cm}$ to $0.90 \pm$ $0.07 \mathrm{~cm}$ ) respectively. The mean difference of WHR was found nonsignificant in both groups. Whereas in the control group, it was the same in the male group $(0.94 \pm 0.87 \mathrm{~cm}$ to $0.94 \pm 0.89 \mathrm{~cm})$.

The mean value of mid-upper arm circumference was increased in male badminton athletes at post-intervention $(12.89 \pm 1.2 \mathrm{~cm}$ to $13.32 \pm 1.05 \mathrm{~cm}$ ) and the mean difference was found statically sig- 
Impact of Dietary Counseling on the Anthropometric Indices, Biochemical Profile, and Sports Performance of Adolescent Badminton Players

nificant $(\mathrm{P}<0.03)$. while in the control male athletes group it was improved by $(12.85 \pm 1.13 \mathrm{~cm}$ to $13.10 \pm 1.04 \mathrm{~cm})$ and the difference was statically significant $(\mathrm{P}<0.03)$. A similar finding was observed in mid-arm muscle circumference in the male athletes' group, and it was enhanced by $(6.63 \pm 1.00 \mathrm{~cm}$ to $6.66 \pm 0.52 \mathrm{~cm})$ respectively. But it was found non-significant. Hence, it was concluded from the intervention study that male badminton athletes improved their muscle circumference compare to female athletes.

The mean waist circumference of female athletes in the control group (10-12 years) was $(27.99 \pm 4.11 \mathrm{~cm}$ to $28.23 \pm 4.05 \mathrm{~cm})$ and in the male group $(28.81 \pm 5.83$ to $28.94 \pm 5.73)$ respectively. Also, in the experimental group, both male and female athletes had increased waist circumference ratio, but it was seen higher in the female experiential group $(26.83 \pm 2.95 \mathrm{~cm}$ to $27.52 \pm 3.38 \mathrm{~cm})$, so it results here that female had a higher waist circumference ratio compare to male badminton athletes (Table 2).

The mean hip circumference of the male badminton athlete was $31.89 \pm 3.37 \mathrm{~cm}$ to $31.78 \pm 3.23 \mathrm{~cm}$ at pre to post-intervention whereas, in the female badminton group, the mean hip circumference was increased from $31.93 \pm 3.28 \mathrm{~cm}$ to $32.18 \pm 3.76 \mathrm{~cm}$, respectively. Although in the control group there was a slight reduction in the mean value of hip circumference $(32.75 \pm 4.34 \mathrm{~cm}$ to $32.57 \pm$ $4.45 \mathrm{~cm}$ ) in the female group (Table 1).

Skinfold thickness assesses body fat and measures fat distribution. At pre-intervention, the skinfold thickness of female athletes was $13.42 \pm 3.64 \mathrm{~cm}$ and reduced at post-intervention $13.3 \pm$ $2.82 \mathrm{~cm}$. whereas in the male experimental group it was increased from $13.43 \pm 3.77 \mathrm{~cm}$ to $13.49 \pm 3.64 \mathrm{~cm}$, respectively. In the control group, it was reduced in both the groups. The other parameters like BMI, WHR, MUAC, WC, and MAMC also improved but the results were not statistically significant.

The changes in biochemical profile before and after intervention are depicted in table 3 . The mean hemoglobin levels, calcium and vitamin D levels increased after 12 weeks of nutrition intervention in girls, although the change was not statistically significant.

Table 3 depicts the mean value of biochemical test in badminton athletes age 10-12 years. The mean value of hemoglobin was increased after intervention $13.21 \pm 7.4 \mathrm{mg} / \mathrm{dl}$ to $13.74 \pm 8.48 \mathrm{mg} / \mathrm{dl}$ and found statically significant $(\mathrm{P}<0.04)$. Serum calcium and vitamin D also improved but they were not found statically significant.

\begin{tabular}{|c|c|c|c|c|c|c|}
\hline \multirow{2}{*}{ Variable } & \multicolumn{3}{|c|}{ Control } & \multicolumn{3}{|c|}{ Experimental } \\
\hline & Pre & Post & t value & Pre & Post & t value \\
\hline Weight(kg) & $\begin{array}{c}44.60 \pm \\
16.06\end{array}$ & $\begin{array}{c}45.39 \pm \\
12.70\end{array}$ & $2.77^{*}$ & $\begin{array}{c}43.48 \pm \\
10.66\end{array}$ & $\begin{array}{l}44.1 \pm \\
10.31\end{array}$ & $3.42^{*}$ \\
\hline Height $(\mathrm{cm})$ & $\begin{array}{c}148.52 \pm \\
12.5\end{array}$ & $\begin{array}{c}148.71 \pm \\
12.4\end{array}$ & $3.61 \mathrm{NS}$ & $\begin{array}{c}147.23 \pm \\
9.14\end{array}$ & $\begin{array}{l}148.71 \\
\pm 9.71\end{array}$ & $7.13^{* *}$ \\
\hline $\begin{array}{l}\text { BMI }(\mathrm{kg} / \\
\left.\mathrm{m}^{2}\right)\end{array}$ & $\begin{array}{c}19.74 \pm \\
3.8\end{array}$ & $\begin{array}{c}19.87 \pm \\
3.74\end{array}$ & $2.44^{*}$ & $\begin{array}{c}19.84 \pm \\
3.66\end{array}$ & $\begin{array}{r}19.76 \\
\pm 3.25\end{array}$ & $1.04 \mathrm{NS}$ \\
\hline WHR (cm) & $\begin{array}{c}0.94 \pm \\
0.87\end{array}$ & $0.94 \pm 0.89$ & $0.101 \mathrm{NS}$ & $\begin{array}{c}0.88 \pm \\
0.08\end{array}$ & $\begin{array}{c}0.90 \pm \\
0.07\end{array}$ & $2.71 \mathrm{NS}$ \\
\hline $\operatorname{MUAC}(\mathrm{cm})$ & $\begin{array}{c}12.85 \pm \\
1.13\end{array}$ & $\begin{array}{c}13.10 \pm \\
1.04\end{array}$ & $2.13^{*}$ & $\begin{array}{c}12.89 \pm \\
1.2\end{array}$ & $\begin{array}{r}13.32 \\
\pm 1.05 \\
\end{array}$ & $2.2^{*}$ \\
\hline MAMC $(\mathrm{cm})$ & $\begin{array}{c}6.39 \pm \\
0.59\end{array}$ & $6.35 \pm 1.23$ & $0.156 \mathrm{NS}$ & $\begin{array}{c}6.63 \pm \\
1.00\end{array}$ & $\begin{array}{c}6.66 \pm \\
0.52\end{array}$ & $0.22 \mathrm{NS}$ \\
\hline $\mathrm{WC}(\mathrm{cm})$ & $\begin{array}{c}28.81 \pm \\
5.83\end{array}$ & $\begin{array}{c}28.94 \pm \\
5.73\end{array}$ & $1.03 \mathrm{NS}$ & $\begin{array}{c}28.67 \pm \\
4.45\end{array}$ & $\begin{array}{r}28.83 \\
\pm 4.03 \\
\end{array}$ & $0.8 \mathrm{NS}$ \\
\hline $\mathrm{HC}(\mathrm{cm})$ & $\begin{array}{c}31.05 \pm \\
3.98\end{array}$ & $31.06 \pm 3.9$ & $0.16 \mathrm{NS}$ & $\begin{array}{c}31.89 \pm \\
3.37\end{array}$ & $\begin{array}{r}31.78 \\
\pm 3.23 \\
\end{array}$ & $0.5 \mathrm{NS}$ \\
\hline SFT $(\mathrm{cm})$ & $\begin{array}{c}13.68 \pm \\
3.33\end{array}$ & $\begin{array}{c}13.38 \pm \\
2.37\end{array}$ & $0.78 \mathrm{NS}$ & $\begin{array}{c}13.43 \pm \\
3.77\end{array}$ & $\begin{array}{r}13.49 \\
\pm 3.64\end{array}$ & $0.12 \mathrm{NS}$ \\
\hline
\end{tabular}

Table 2: Mean anthropometric measurements of male badminton players.

NS- non-significant, *Significant, **Highly Significant.

\begin{tabular}{|l|c|c|c|c|c|c|}
\hline \multirow{2}{*}{ Variable } & \multicolumn{3}{|c|}{ Control } & \multicolumn{2}{c|}{ Experimental } \\
\cline { 2 - 7 } & Pre & Post & t value & Pre & Post & $\begin{array}{c}\text { t } \\
\text { value }\end{array}$ \\
\hline $\begin{array}{l}\text { Hemoglobin } \\
\text { (mg/dl) }\end{array}$ & $\begin{array}{c}12.28 \pm \\
0.98\end{array}$ & $\begin{array}{c}12.46 \pm \\
0.77\end{array}$ & $1.66 \mathrm{NS}$ & $\begin{array}{c}13.21 \pm \\
7.4\end{array}$ & $\begin{array}{c}13.74 \\
\pm 8.48\end{array}$ & $0.8^{*}$ \\
$11.5-15.5 \mathrm{~g} / \mathrm{dl}$ & & & & & & \\
\hline Serum & & & & $9.28 \pm$ & $9.32 \pm$ & $0.6 \mathrm{NS}$ \\
Calcium (mg) & $9.12 \pm$ & $9.21 \pm$ & $0.836 \mathrm{NS}$ & 0.46 & 0.29 & \\
$8.7-10.7 \mathrm{mg} /$ & 0.47 & 0.62 & & & & \\
dl & & & & $12.9 \pm$ & 13.52 & $1.3 \mathrm{NS}$ \\
\hline $\begin{array}{l}\text { Vitamin D } \\
\text { (ug/dl) }\end{array}$ & $11.40 \pm$ & $11.52 \pm$ & $0.868 \mathrm{NS}$ & 5.59 & \pm 7.15 & \\
\hline
\end{tabular}

Table 3: Mean biochemical parameters of female badminton players.

NS- Non-significant, *Significant. 


\begin{tabular}{|c|c|c|c|c|c|c|}
\hline \multirow{2}{*}{ Variable } & \multicolumn{3}{|c|}{ Control } & \multicolumn{3}{|c|}{ Experimental } \\
\hline & Pre & Post & t value & Pre & Post & t value \\
\hline $\begin{array}{l}\text { Hemoglobin } \\
11.5-15.5 \mathrm{~g} / \mathrm{dl}\end{array}$ & $\begin{array}{c}13.69 \pm \\
6.49\end{array}$ & $\begin{array}{c}13.88 \pm \\
6.45\end{array}$ & $2.35 \mathrm{NS}$ & $\begin{array}{c}12.72 \pm \\
1.23\end{array}$ & $\begin{array}{c}12.86 \\
\pm 1.1\end{array}$ & $0.07^{*}$ \\
\hline $\begin{array}{l}\text { Serum Calcium } \\
(\mathrm{mg}) \\
8.7-10.7 \mathrm{mg} / \\
\mathrm{dl}\end{array}$ & $\begin{array}{c}9.13 \pm \\
0.47\end{array}$ & $\begin{array}{c}9.23 \pm \\
0.41\end{array}$ & $1.88^{*}$ & $\begin{array}{l}9.34 \pm \\
0.424\end{array}$ & $\begin{array}{l}9.39 \pm \\
0.309\end{array}$ & $0.444 \mathrm{NS}$ \\
\hline $\begin{array}{l}\text { Vitamin D (ug/ } \\
\text { dl) }\end{array}$ & $\begin{array}{c}11.67 \pm \\
1.08\end{array}$ & $=\begin{array}{c}11.77 \pm \\
1.16\end{array}$ & $0.44 \mathrm{NS}$ & $\begin{array}{c}13.36 \pm \\
18.77\end{array}$ & $\begin{array}{c}14.56 \\
\pm \\
26.60\end{array}$ & $0.349 \mathrm{NS}$ \\
\hline
\end{tabular}

Table 4: Mean biochemical parameters of male badminton players.

NS- Non-significant, *Significant.

Table 4 describes the mean difference of hemoglobin level and calcium level of male adolescent athletes in the experimental group that was improved $(12.72 \pm 1.23 \mathrm{~g} / \mathrm{dl}$ to $12.86 \pm 1.1 \mathrm{~g} / \mathrm{dl})$ and $(9.34$ $\pm 0.42 \mathrm{mg}$ to $9.39 \pm 0.3 \mathrm{mg}$ ) from pre to post-intervention. The improvement in hemoglobin was statistically significant in the experimental group $(\mathrm{P}<0.02)$.
Sports performance

The raw data converted into cumulative score category and categories fall in to excellent (8-10), (6-8) good, (4-6) average and, below $(4<)$ poor. The below table describes the flexibility, shuttle runs, agility, 50-yard desk, and sits up of female and male badminton athletes age group of 10-, 11-, and 12-years. Results revealed that the flexibility of badminton athletes was improved in the age group of 10 years (male and female), 11 (male) and 12 (male) years after the intervention in the experimental group and develop better muscle flexibility results in a positive impact on skeletal health of adolescents and cardiorespiratory fitness increases bone formation and bone resorption in pre-adolescent females.

Flexibility is also known as sit and reach test, we found out that this fitness score was improved after nutrition intervention in both male and female in the experimental group in the age group of 12 years, 11 years and 10 years and it was observed that all athletes were in excellent category. However, in the age group of 12 years, male athlete was shifted from good to excellent category. Similarly, in the control group, the flexibility was improved in 12 and 11 years. But in 10-year female group it was reduce that may lead to injury.

\begin{tabular}{|c|c|c|c|c|c|c|c|c|c|c|c|c|}
\hline \multirow{3}{*}{ Variable } & \multicolumn{4}{|c|}{ Female 10 years } & \multicolumn{4}{|c|}{ Female 11 years } & \multicolumn{4}{|c|}{ Female 12 years } \\
\hline & \multicolumn{2}{|c|}{ Control } & \multicolumn{2}{|c|}{ Experiment } & \multicolumn{2}{|c|}{ Control } & \multicolumn{2}{|c|}{ Experiment } & \multicolumn{2}{|c|}{ Control } & \multicolumn{2}{|c|}{ Experiment } \\
\hline & Pre & Post & Pre & Post & Pre & Post & Pre & Post & Pre & Post & Pre & Post \\
\hline Flexibility (sec.) & 6.5 & 6 & 8.8 & 9.1 & 7.3 & 8 & 9.7 & 10 & 5.6 & 6 & 7.3 & 7.7 \\
\hline Shuttle Run (sec.) & 9 & 9.5 & 8.2 & 9.7 & 9.3 & 10 & 9.1 & 10 & 9.2 & 10 & 10 & 9.7 \\
\hline 50 Yard (sec.) & 5.5 & 6.5 & 8.5 & 9.14 & 8.6 & 8.6 & 7.1 & 7.4 & 4.4 & 10 & 5.5 & 6.4 \\
\hline $\begin{array}{l}\text { Standing Broad } \\
\text { Jump (sec.) }\end{array}$ & 6.5 & 8 & 6.5 & 6 & 6.5 & 6.6 & 6.8 & 7.1 & 9.2 & 9.2 & 5.3 & 5.7 \\
\hline Speed (sec.) & 8 & 9.5 & 8.2 & 8 & 8 & 10 & 8 & 8 & 8 & 10 & 9.7 & 8.6 \\
\hline
\end{tabular}

Table 5: Mean sports performance score of female athletes.



Figure a
The shuttle run is defined as running till maximal voluntary exhaustion. In the age group of 12 years and 11 years the maximal voluntary exhaustion capacity was improved in the female group (excellent, 8.2-9.7) as compare to 11 years (excellent, 8.7-9.4) male athletes (Table 5). Whereas in the age group of 10 years they remained in the same category and in the control group it was increased in female group. So, it is concluded here that both male and females had greater performance in the shuttle run test and shifted in the excellent category after nutrition intervention. 


\begin{tabular}{|c|c|c|c|c|c|c|c|c|c|c|c|c|}
\hline \multirow{3}{*}{ Variable } & \multicolumn{4}{|c|}{ Male 10 years } & \multicolumn{4}{|c|}{ Male 11 years } & \multicolumn{4}{|c|}{ Male 12 years } \\
\hline & \multicolumn{2}{|c|}{ Control } & \multicolumn{2}{|c|}{ Experiment } & \multicolumn{2}{|c|}{ Control } & \multicolumn{2}{|c|}{ Experiment } & \multicolumn{2}{|c|}{ Control } & \multicolumn{2}{|c|}{ Experiment } \\
\hline & Pre & Post & Pre & Post & Pre & Post & Pre & Post & Pre & Post & Pre & Post \\
\hline Flexibility & 6.2 & 6.5 & 8.9 & 9.7 & 5.5 & 5 & 8.7 & 9.4 & 6.2 & 6.5 & 7.6 & 8 \\
\hline Shuttle Run & 9.1 & 9.7 & 10 & 10 & 10 & 10 & 10 & 9.8 & 8 & 8 & 8.3 & 8 \\
\hline 50 yards & 6 & 7.1 & 7.2 & 7.8 & 5.5 & 6 & 7.2 & 8.1 & 7.7 & 6.5 & 7.6 & 7.6 \\
\hline Standing broad jump & 10 & 10 & 10 & 10 & 5 & 7.5 & 6.5 & 6.1 & 7.7 & 7.7 & 7.2 & 7 \\
\hline Speed & 9.4 & 9.7 & 8.2 & 8.6 & 8.5 & 9.5 & 7.2 & 8.5 & 8.2 & 9.7 & 8.5 & 8.3 \\
\hline
\end{tabular}

Table 6: Mean sports performance score of male athletes.

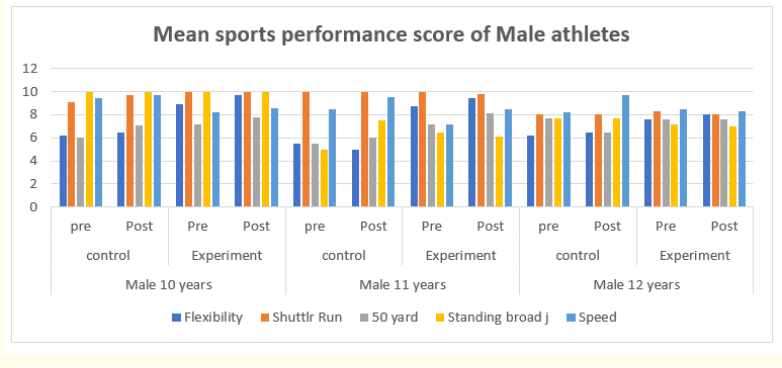

Figure b

Standing broad jump improves the leg power and sports performance of an athlete. The physical performance was improved slightly among the athlete groups. so overall both male and female adolescent athletes had average sports performance.

50-yard desk measures speed and 10-year male group and 11year female group improved their speed and performed excellent in this test (Table 6). While in the other groups it has remained at average category. Hence, both male and female athlete performed better in this (50-yard desk) test.

The average number of speeds completed by the 10 -year-old female- to 11-year-old male students was greater, whereas the 12-year-old students performed average to excellent (8 to 8, 8.5- 8, male) and (8.2-8.6, 7.2-8.5, female) in the speed test according to the national norms.

\section{Discussion}

Involvement in sport or games is positively linked with sports performance and physical fitness. Battista., et al. 2020 explored that how participation in physical activity in early childhood and early adolescence affects high school participation. Students were selected from the Michigan State University and their performance test for study selected was sit and reach test, shuttle run test, jump, and reach test, standing long jump, agility, and 50-yard dash. Shuttle run test and agility were selected for both boys and girls while long jump and 50-yard dash test included only for boys. Battista., et al. concluded that participation in games or sport in early childhood and adolescents increases the likelihood of high school participation [23].

Similar study was conducted on adolescent and their sports performance found that after three-month completion of the intervention diet, High-intensity interval training group significantly improved body fat, and body mass index while nutrition advice only reduces body mass index, and body fat in adolescent overweight girls [24].

Shuttle run test is an appropriate test to examine physical fitness among adolescents because it helps in better reproducibility. A study states that there is significant decline in shuttle run test by nine percent in girls and seven percent in boys and poor shuttle run performance linked to increase body mass index [25].

\section{Conclusion}

The present study is examining anthropometric, biochemical and sports performance of badminton athletes. The variable that improved over the period of 12-week nutrition intervention in the badminton athlete was flexibility, standing broad jump, power, strength and speed, Weight and height, hemoglobin, calcium, and vitamin D.

Citation: Arpana Indoria and Nimali Singh. "Impact of Dietary Counseling on the Anthropometric Indices, Biochemical Profile, and Sports Performance of Adolescent Badminton Players". Acta Scientific Nutritional Health 5.9 (2021): 30-39. 
Improved muscular fitness and flexibility, agility, speed, and cardiorespiratory fitness have positive impact on overall health. Pre-adolescent should encourage to participate in sports and daily exercise to maintain pubertal development and achieve maximum bone mass. Schools and academies have an important role to recognize students with lower fitness levels and they should promote to be active and participate in an at least one game. There is an improvement in the anthropometric, biochemical, and physical fitness score among adolescents.

\section{Bibliography}

1. Dr Rajiv Sighamoney., et al. "Effect of core strengthening on dynamic balance and agility in badminton players". International Journal of Physical Education, Sports and Health 5.1 (2018): 8688.

2. Takuya Sonada., et al. "Relationship between agility and lower limbs muscle strength, targeting university badminton players". Physical Therapy Sciences 30 (2018): 320-323.

3. Young WB., et al. "Agility and change of direction speed are independent skills: implication for training for agility in invasion sports". International Journal of Sports Science Medicine 12 (2013): 97-103.

4. Tomoko Okada., et al. "Relationship between core stability, functional movement, and performance". Journal of Strength and Conditioning Research 25.1 (2011): 252-261.

5. Hoppe MW., et al. "Relationship betwwen core strength and key variables of performance in elite rink hockey players". Journal of Sports Medicine Physical Fitness 55.3 (2015): 150-157.

6. Morris T and Roychowdhury D. "Physical activity for health and wellbeing: the role of motives for participation". Health Psychology Report 8.1 (2020): 391-407.

7. Stratton G and Oliver JL. "The impact of growth and maturation on physical performance". In: Strength and Conditioning for Young Athletes: Science and Application. Lloyd RS, Oliver JL, eds. New York: Routledge (2019): 3-20.

8. Jordan SL., et al. "Micronutrient Deficiency in Athletes and Inefficiency of Supplementation: Is Low Energy Availability a Culprit?" Pharma Nutrition 14 (2020): 100229.
9. FAO/WHO/UNU. Human Energy Requirements: Report of a Joint FAO/WHO/ UNU Expert Consultation. (2001).

10. Loucks AB., et al. "Energy availability in athletes". Journal of Sports Science 29 (2011): S7-S15.

11. Koehler K., et al. "Comparison of self-reported energy availability and metabolic hormones to assess adequacy of dietary energy intake in young elite athletes". Applied Physiology, Nutrition, and Metabolism 38 (2013): 725-733.

12. Phillips SM., et al. "Ingesting a 6\% carbohydrate-electrolyte solution improves endurance capacity, but not sprint performance, during intermittent, high intensity shuttle running in adolescent team games players aged 12-14 years". European Journal of Applied Physiology 109 (2010): 811-821.

13. De' combaz J., et al. "Fructose and galactose enhance postexercise human liver glycogen synthesis". Medicine and Science in Sports and Exercise 43 (2011): 1964-1971.

14. Michelfelder AJ. "Soy: A complete source of protein". American Family Physician 79 (2009): 43-47.

15. Karagounis LG., et al. "Protein intake at breakfast promotes a positive whole body protein balance in a dose-response manner in healthy children: A randomized trial". Journal of Nutrition 148 (2018): 729-737.

16. J Aucouturier., et al. "Fat and carbohydrate metabolism during submaximal exercise in children". Sports Medicine 38.3 (2008): 213-238.

17. Hannon M P., et al. "Energy and Macronutrient Considerations for Young Athletes". Strength and Conditioning Journal 42.6 (2020): 109-119.

18. JohnEric W Smith., et al. "Nutritional Considerations for Performance in Young Athletes". Journal of Sports Medicine 2015 (2015): 13.

19. Schlegel EK. "Prevention of hypernatremia and hyponatremia in marathon runners (Doctoral dissertation, Boston University)" (2020).

20. https://www.hullandeastridingperformancecentre.co.uk/nutrition/fluid-requirements-training-competitions/ 
21. A C Ross., et al. "The 2011 report on dietary reference intakes for calcium and vitamin D from the institute of medicine: what clinicians need to know". Journal of Clinical Endocrinology and Metabolism 96.1 (2011): 53-58.

22. Zhang F., et al. "Physical fitness reference standards for Chinese children and adolescents". Scientific Reports 11.1 (2021): 1-12.

23. http://fitorfad.weebly.com

24. Battista R A., et al. "Childhood physical fitness and performance as predictors of high school sport participation". Measurement in Physical Education and Exercise Science 25.1 (2021): 43-52.

25. Plavsic L., et al. "Effects of high-intensity interval training and nutrition advice on cardiometabolic markers and aerobic fitness in adolescent girls with obesity". Applied Physiology, Nutrition, and Metabolism 45.3 (2020): 294-300.

26. Stratton G., et al. "Cardiorespiratory fitness and body mass index of 9-11-year-old English children: a serial cross-sectional study from 1998 to 2004". International Journal of Obesity 31 (2007): 1172-1178.

\section{Volume 5 Issue 9 September 2021}

(C) All rights are reserved by Arpana Indoria and Nimali Singh. 